\title{
Three strategies to foster diversity in the food movement
}

COMMENTARY ON RACE AND ETHNICITY IN FOOD SYSTEMS

\author{
Hilary King * \\ Emory University
}

Submitted July 16, 2015 / Published online September 18, 2015

Citation: King, H. (2015). Three strategies to foster diversity in the food movement. Journal of Agriculture,

Food Systems, and Community Development, 5(4), 183-187. http://dx.doi.org/10.5304/jafscd.2015.054.030

Copyright (C) 2015 by New Leaf Associates, Inc.

\begin{abstract}
This commentary explores strategies for coalitionbuilding and reallocating resources across racial divides within alternative food systems. Following analysis of a set of public conversations held in Atlanta, Georgia, in spring 2015, I identify three strategies that may promote greater diversity: (1) the allocation of institutional and academic resources beyond historically privileged spaces; (2) the development of a shared historical context for framing and shaping collaborative, antiracist work; and (3) the commitment of policy-makers to execute the ideas of food producers. These
\end{abstract}

* Hilary King, Department of Anthropology, Emory University; 1557 Dickey Drive; Atlanta, Georgia 30307 USA; +1-541-778-4631; hbking@emory.edu

\section{Disclosure}

Hilary King, primary author and applied anthropologist, works part-time with Community Farmers Markets, one of the organizations that sponsored the event with Eric HoltGiménez and Grow Where You Are at the King Center in March 2015. strategies, pursued in conjunction, may aid in addressing regional and neighborhood discrepancies in representation in food system leadership and also foster a stronger, antiracist alternative food system.

\section{Keywords}

alternative food systems, Atlanta, coalition, collaboration, diversity, inequity, farmers, food justice, race, racism, strategies

\section{Introduction}

In Atlanta, Georgia, no shortage of racialized history shapes our existing food system. This same history shapes the alternative food systems through which practitioners and academics seek to address the inequity in food access, economic development, and sustainable food production that is disproportionately borne as a result of one's racial identity (Alkon \& Agyeman, 2011; Block, Scribner, \& DeSalvo, 2004; Franco, Diez Roux, Glass, Caballero, \& Brancati, 2008). Evidence demonstrates that discrepancies in access to resources 
correlate with histories of injustice and racism. In the spring 2015 issues of the Journal of Agriculture, Food Systems, and Community Development, Tanaka, Indiano, Soley, and Mooney (2015) examine regional discrepancies in the funding of USDA Community Food Projects Competitive Grant Program (CFPCGP). They find that there is a large regional discrepancy in grant allocation, leaving the Southern region of the U.S. particularly underrepresented in terms of funded projects.

Their findings encouraged me to examine how similar disparities in access to resources may operate on and be addressed on smaller scales, particularly on a citywide level. My analysis of a series of conversations and events held in Atlanta in spring $2015^{1}$ led me to identify three major strategies to respond more comprehensively to the discrepancy highlighted by Tanaka et al. They are: (1) the purposeful allocation of institutional and academic resources beyond historically privileged arenas; (2) the development of a shared historical context in framing and shaping collaborative, antiracist work; and (3) the commitment of those of us in policyrelated positions to act on and execute the ideas of food producers. Cities suffer from many of the same racial and cultural inequities that regions often do. The pursuit of these three strategies, in conjunction, may further the development of a shared system from which to address disparities like those identified by Tanaka et al. (2015).

\section{Allocate Institutional and Academic Resources Beyond "White Space"}

To address racism in our food systems, it is necessary to bring to light the historical and contemporary inequities that exist. It is critical to undertake this project in spaces where people of color and white people can come together to explore this history and confront its ramifications. The spaces that facilitate these interactions may not be within the

\footnotetext{
${ }^{1}$ The identification of these three strategies followed a set of public conversations held in Atlanta in February and March 2015. These consisted of a participatory workshop, "Food System Alchemy," facilitated by Eugene Cooke and Nicole Bluh, hosted at the 2015 Georgia Organics Conference in Athens, Georgia, and the lecture and community discussion, "Dismantling Racism in the Food System," hosted by Eric Holt-Giménez of Food First and the activist growers of
}

institutions that support such explorations. It is critical, therefore, to use institutional and academic resources to bring events, conversation, and explorations beyond the boundaries of those institutions.

In March 2015, Emory University hosted Eric Holt-Giménez of Food First for the lecture, "Dismantling Racism in the Food System." Rather than running a single event, activists at Emory partnered with food system organizations to do an additional version of this event at The Martin Luther King, Jr. Center for Nonviolent Social Change (the King Center), an educational memorial and social change center honoring Martin Luther King, Jr. Though both events were widely publicized, the event at the King Center received much more media attention and a very different spectrum of attendance. The Emory event was attended primarily by students. In contrast, the King Center event drew more than 80 people from across the city. The Emory event was scheduled as a lecture followed by a question and answer period. The King Center event was a short lecture followed by a community discussion. The racial makeup of the audiences differed greatly; at Emory, attendees were primarily white. Attendees at the King Center were primarily people of color, including activists, farmers, academics, community members.

To understand the difference in attendance at these two events, it is useful to examine Anderson's (2015) ideas of "white space" and "black space." Anderson puts forth the idea that although racial integration has progressed since the civil rights movement, overwhelmingly white neighborhoods, schools, restaurants, and public spaces remain. Blacks, and other people of color, may perceive these to be "white spaces" informally off limits to them. To engage in racially inclusive ways, it is critical to move conversations beyond the "white space."

Grow Where You Are, an agricultural social enterprise located in Atlanta. These discussions were small steps in a long history of struggle, intervention, and action by food system activists of color in Atlanta, supported in this instance by the Black Heritage Museum and Cultural Center, Community Farmers Markets, Georgia Organics, Emory University, Food Well Alliance, Grow Where You Are, and Slow Food Atlanta. 
The commitment to follow-up and partnerships following the events also differed. While the Emory event seems not to have produced great further engagement, the King Center event strengthened new partnerships. One example includes a new market being piloted at a public transit station in a historically black neighborhood. This project brings together Atlanta's public transit authority, MARTA; the South West Atlanta Growers Cooperative, made up of primarily black urban farmers; the Atlanta Community Food Bank; and Community Farmers Markets, which is a farmers' market umbrella organization in Atlanta.

The event at the King Center would not have been possible without institutional support for Holt-Giménez's honorarium and travel. However, Holt-Giménez was eager to share his expertise in an alternate setting. Planning community events that take place outside of the traditionally "white spaces" that have financial resources is an important strategy for building relationships and shared knowledge bases across racial and ethnic boundaries in the food system. Such pairings build institutional support and personal collaborations that create more inclusive spaces wherein institutional privilege can and should be challenged.

\section{Build a Shared Historical and Analytical Framework}

Within community discussions that have brought race and racism in our food system to the forefront, many people have lauded an expanded historical context. As stated before, hosting conversations and events that provide this foundation can be fundamental for building partnerships with systemic potential. Holt-Giménez's lectures in spring 2015 reported the problematic history of agricultural industrialization on a global scale. The lecture focused on the fact that current global agricultural systems have largely been built on the backs of people of color and women. Through charts and narratives connecting food riots, stock prices of agroindustry corporations, and profits, the lecture provided an historical and analytical framework that situated existing divisions based on race within the global food system. This context made space for participants in the community discussion to flesh out how such divisions are manifest within Atlanta.

Participants in this discussion expressed empowered sentiments following the examination of this history. One participant observed that, "the majority of the food grown worldwide is grown by people who are not educated through the formal system. They often grow food for other people, on land that used to be their own." This observation was coupled with outcries related to the lack of land available particularly to black farmers in Atlanta. Another participant asked, "What of what we have seen [in the lecture] is being replicated from the global food system here in Atlanta?" This led into a tense discussion about recent grant applications, funded and unfunded. Although these questions were not resolved, the contextualization of these issues in Atlanta within a global context seemed to generate a space to discuss the disparities that underlie some disputes about the allocation of resources and funding that correspond to existing marginalizations.

Kwabena Nkromo, executive director of Atlanta Food and Farm, eloquently expressed this idea, stating,

There is a fundamental need to have an understanding of this history... If we don't have an understanding of this history, then we will always be working from different foundations. We have to work on structures, because it is the structures that oppress us. If we just throw down our hands without understanding the structure, the work that we do will feed into that system.

It is pivotal that we work from a foundation that accounts for the historical contexts in which current food system inequities manifest.

\section{Commit Analysts to Develop and Implement Food Producer's Ideas}

Within the food movement, I am currently given a stipend to work in front of my computer, analyzing inequities in the food system and working to build programs. In Atlanta the paid work of analysis and policy creation within the food system is disproportionately white. My work, however, is also built on the work of the people in the alternative food 
movement who actually grow food and run foodrelated businesses. It is critical in my view that my work as an analyst be grounded in the solutions developed by the people producing the food in the food movement. Many are people of color. To know their ideas, it is necessary for me as an analyst to follow the two steps above to build relationships. The next step is to follow through on using my position to advance ideas that they deem most useful and which may produce some structural change.

During the conversations that are the basis for this commentary, Eugene Cooke, activist farmer at Grow Where You Are, a social-enterprise educational farm in South West Atlanta, called for microscale structural reforms. He asked young people who are salaried and working in advocacy and policy-based organizations to develop their own microgrant programs by pooling and allocating 3 percent of their incomes to support a farmer, provide grant-writing assistance, or address another need outside of bureaucratic or competitive funding opportunities.

Cooke also advocated for expanding the HUD Good Neighbor Next Door program, which makes certain single-family homes available to law enforcement officers, public school teachers, firefighters, and emergency medical technicians (EMTs) at a substantial discount, provided they agree to live in those homes for at least 36 months. Atlanta had more than 30,000 vacant homes in 2012 - homes that could be made available to farmers through an expanded Good Neighbor Next Door program. Cooke and others like him are busy farming and do not have time to do the logistical work to submit these types of ideas to the USDA's competitive funding program that was analyzed by Tanaka et al. Ideas such as these come out of the needs and work of the people building our alternative food system. Many of the best ideas come from those who are most marginalized within both conventional and alternative agricultural systems. Many of us who have salaried work come from backgrounds of privilege. It is our responsibility as people with analytical jobs aimed at building a more just food system to bring ideas such as these, offered by people whose positions are more precarious, to fruition.
A unique limitation of working with farmers is that they want to be farmers; they lack time to develop programs that may best serve them. It is the responsibility of those of us who work to systematize and develop policy to connect with and pay attention to these food producers, and to shape our analyses and programs accordingly. Many people who work in the food system, as producers or food workers, continue to be people of color and those who are historically marginalized. Those of us who are paid to think about food systems have the privilege of doing so because of their work. It is therefore critical that we know them, and work from their knowledge and observations. If we fail to do so, we cannot build the more just, inclusive food system that we hope to build.

\section{Conclusion}

The three crucial actions above are interrelated processes that build on each other to strengthen and implement the most innovative ideas in alternative food systems. These approaches work to connect policy-makers, resources, and food producers in our cities and our regions, sharing expertise while addressing the racialized and marginalizing context in which alternative food systems must function. Such approaches may aid those of us in the U.S. South to garner the greater institutional support that Tanaka et al. identified as lacking. Such support will facilitate building on the antiracist, socially embedded, engaged work that is already being done in our region, and lead us toward a more just and sustainable food system for all.

\section{Acknowledgements}

I would like to thank and acknowledge many of the activists, scholars, and farmers whose work indirectly and directly shaped this article, particularly Colleen Morich, Daniel Crain, Eric Holt-Giménez, Eugene Cooke, Imran Battla, Jovanna Johnson-Cooke, Katie Hayes, Kim Karris, Peter Morich, Nicole Bluh, Tamara Jones, and Sarah Franzen.

\section{References}
Alkon, A. H., \& Agyeman, J. (2011). Cultivating food justice: race, class, and sustainability. Cambridge, Massachusetts: MIT Press.


Anderson, E. (2015). “The White Space.” Sociology of Race and Ethnicity, 1(1), 10-21. http://sre.sagepub.com/

Block, J. P., Scribner, R. A., \& DeSalvo, K. B. (2004). Fast food, race/ethnicity, and income: A geographic analysis. American Journal of Preventive Medicine, 27(3), 211-217. http://dx.doi.org/10.1016/j.amepre.2004.06.007

Franco, M., Diez Roux, A. V., Glass, T. A., Caballero, B., \& Brancati, F. L. (2008). Neighborhood characteristics and availability of healthy foods in
Baltimore. American Journal of Preventive Medicine, 35(6), 561-567.

http://dx.doi.org/10.1016/j.amepre.2008.07.003 Tanaka, K., Indiano, E., Soley, G., \& Mooney, P. H. (2015). Building the capacity for community food work: The geographic distribution of USDA Community Food Projects Competitive Grant Program grantees. Journal of Agriculture, Food Systems, and Community Development, 5(3), 97-111. http://dx.doi.org/10.5304/jafscd.2015.053.006 